\title{
Discrimination of DNA and RNA in cells by a vital fluorescent probe: Lifetime imaging of SYTO13 in healthy and apoptotic cells.
}

Citation for published version (APA):

van Zandvoort, M. A. M. J., de Grauw, C. J. ., Gerritsen, H. C., Broers, J. L. V., Oude Egbrink, M. G. A., Ramaekers, F. C. S., \& Slaaf, D. W. (2002). Discrimination of DNA and RNA in cells by a vital fluorescent probe: Lifetime imaging of SYTO13 in healthy and apoptotic cells. Cytometry, 47, 226-235.

https://doi.org/10.1002/cyto.10076

Document status and date:

Published: 01/01/2002

DOI:

10.1002/cyto. 10076

Document Version:

Publisher's PDF, also known as Version of record

Please check the document version of this publication:

- A submitted manuscript is the version of the article upon submission and before peer-review. There can be important differences between the submitted version and the official published version of record.

People interested in the research are advised to contact the author for the final version of the publication, or visit the DOI to the publisher's website.

- The final author version and the galley proof are versions of the publication after peer review.

- The final published version features the final layout of the paper including the volume, issue and page numbers.

Link to publication

\footnotetext{
General rights rights.

- You may freely distribute the URL identifying the publication in the public portal. please follow below link for the End User Agreement:

www.umlib.nl/taverne-license

Take down policy

If you believe that this document breaches copyright please contact us at:

repository@maastrichtuniversity.nl

providing details and we will investigate your claim.
}

Copyright and moral rights for the publications made accessible in the public portal are retained by the authors and/or other copyright owners and it is a condition of accessing publications that users recognise and abide by the legal requirements associated with these

- Users may download and print one copy of any publication from the public portal for the purpose of private study or research.

- You may not further distribute the material or use it for any profit-making activity or commercial gain

If the publication is distributed under the terms of Article $25 \mathrm{fa}$ of the Dutch Copyright Act, indicated by the "Taverne" license above, 


\title{
Discrimination of DNA and RNA in Cells by a Vital Fluorescent Probe: Lifetime Imaging of SYTO13 in Healthy and Apoptotic Cells
}

\author{
Marc A.M.J. van Zandvoort, ${ }^{1 *}$ Cees J. de Grauw, ${ }^{2}$ Hans C. Gerritsen, ${ }^{2}$ Jos L.V. Broers,,${ }^{3,4}$ \\ Mirjam G.A. oude Egbrink, ${ }^{5}$ Frans C.S. Ramaekers, ${ }^{3}$ and Dick W. Slaaf ${ }^{1,4}$ \\ ${ }^{1}$ Department of Biophysics, Cardiovascular Research Institute Maastricht, University of Maastricht, \\ Maastricht, The Netherlands \\ ${ }^{2}$ Department of Biophysics, Debye Institute, University of Utrecht, Utrecht, The Netherlands \\ ${ }^{3}$ Department of Molecular Cell Biology, Cardiovascular Research Institute Maastricht, University of Maastricht, \\ Maastricht, The Netherlands \\ ${ }^{4}$ Faculty of Biomedical Engineering, Eindhoven University of Technology, Eindhoven, The Netherlands \\ ${ }^{5}$ Department of Physiology, Cardiovascular Research Institute Maastricht, University of Maastricht, \\ Maastricht, The Netherlands
}

Received 2 April 2001; Revision Received 14 December 2001; Accepted 18 December 2001

\begin{abstract}
Background: Of the few vital DNA and RNA probes, the SYTO dyes are the most specific for nucleic acids. However, they show no spectral contrast upon DNA or RNA binding. We show that fluorescence lifetime imaging using two-photon excitation of SYTO13 allows differential and simultaneous imaging of DNA and RNA in living cells, as well as sequential and repetitive assessment of staining patterns.
\end{abstract}

Methods: Two-photon imaging of SYTO13 is combined with lifetime contrast, using time-gated detection. We focus on distinguishing DNA and RNA in healthy and apoptotic Chinese hamster ovary cells.

Results: In healthy cells, SYTO13 has a fluorescence lifetime of $3.4 \pm 0.2 \mathrm{~ns}$ when associated with nuclear DNA. Bound to RNA, its lifetime is $4.1 \pm 0.1 \mathrm{~ns}$. After induction of apoptosis, clusters of SYTO13 with fluorescence lifetime of $3.4 \pm 0.2 \mathrm{~ns}$ become apparent in the cytoplasm. They are identified as mitochondrial DNA on the basis of colocalization experiments with the DNA-specific dye, DRAQ5, and the mitochondrial-specific dye, CMXRos. Upon progression of apoptosis, the lifetime of SYTO13 attached to DNA shortens significantly, which is indicative of changes in the molecular environment of the dye.

Conclusions: We have characterized SYTO13 as a vital lifetime probe, allowing repetitive and differential imaging of DNA and RNA. Cytometry 47:226-235, 2002.

(C) 2002 Wiley-Liss, Inc.

Key terms: SYTO13; apoptosis; two-photon microscopy; fluorescence lifetime; energy transfer; vital imaging
Simultaneous and differential imaging of dynamic properties of DNA and RNA in various compartments of vital cells is of interest for a number of reasons. For example, visualization of the compartmentalization of transcriptional activity in the nucleus of living cells is still difficult with the nucleic acid probes available (1). These dyes often exhibit similar affinities for DNA and RNA. In addition, the aggregation, cleavage, and segregation of DNA in the apoptotic nucleus (2) cannot be studied properly in living cells in combination with changes in RNA structure. This is because no vital imaging probes are available that distinguish nuclear DNA from nucleolar RNA or from mitochondrial DNA. Therefore, segregation of nuclear DNA and RNA to the cytoplasm is difficult to monitor. Studying the dynamics of nucleic acid behavior in living cells will benefit greatly from probes or methods that allow the separate, but simultaneous, detection of DNA and RNA (3-5).
Spectroscopic or lifetime contrast may be used to distinguish the binding sites of a fluorescent probe. In spectroscopic imaging $(6,7)$ differences in fluorescence intensity at two excitation or various emission wavelengths are detected. In lifetime imaging (8-14), the typical time constant of the fluorescence decay processes is used as the contrast mechanism. Both principles can be applied for the simultaneous imaging of multiple probes or for a single probe that exhibits different spectral or lifetime properties, depending on its binding partner.

*Correspondence to: Marc A.M.J. van Zandvoort, Department of Biophysics, Cardiovascular Research Institute Maastricht, University of Maastricht, PO Box 616, 6200 MD Maastricht, The Netherlands.

E-mail: MAMJ.vanZandvoort@BF.unimaas.nl

Published online in Wiley InterScience (www.interscience.wiley.com). DOI: $10.1002 /$ cyto. 10076 
Because only few vital imaging probes are available that bind exclusively to either DNA or RNA, the use of a single probe is preferred. Probes of the SYTO family $(15,16)$ are cell-permeable nucleic acid stains with varying characteristics, such as cell permeability, fluorescence enhancement upon binding, excitation and emission spectra, and DNA/RNA binding affinity. However, they exhibit no spectral contrast in binding to DNA or RNA. Therefore, the question arises: Do the SYTO probes exhibit lifetime contrast on binding sites?

The fluorescence lifetime of a probe is independent of characteristics that do modulate the detected fluorescence intensity (e.g., laser intensity fluctuations, photobleaching, probe leakage, out-of-focus movements). On the other hand, it can be sensitive to chemical parameters in its environment, like $\mathrm{pH}(14,17-19)$ and ion or oxygen concentrations $(12,20-27)$. It may yield quantitative information about the local chemical environment and state of the fluorescent molecules in the cell $(13,14,28-30)$ and therefore offer a tool to discriminate between DNA and RNA-bound SYTO dyes.

We applied a combination (31) of fluorescence lifetime imaging and two-photon excitation to study the effect of binding of DNA and RNA on the properties of one of the SYTO probes, i.e., SYTO13. Two-photon excitation microscopy (32) is now used widely in life sciences (33-36). It not only has an intrinsically high axial resolution (37) without the need of a confocal pinhole in the detection path, but its use can also significantly reduce cell damage, both due to the use of longer wavelength excitation light (avoiding the use of damaging UV or blue excitation light) and the reduction of out-of-focus irradiation $(38,39)$. This makes two-photon fluorescence microscopy very suitable for the repetitive imaging of cells $(35,39)$, without seriously affecting their vitality. Because two-photon microscopy requires the use of femtosecond pulsed lasers (32), the combination of two-photon and lifetime contrast imaging with the application of the time-gated detection technique (14) is straightforward.

SYTO13 (15) becomes fluorescent when bound to DNA or RNA. The quantum yields are equal when bound to RNA and DNA, its excitation spectrum has a maximum at $488 \mathrm{~nm}$, and the emission spectrum peaks at $510 \mathrm{~nm}$. Also, the binding affinity characteristics for DNA and RNA are comparable. Finally, SYTO13 labels DNA, both in the nucleus and in the mitochondria, and RNA in the cytoplasm and nucleoli. Our study was carried out in healthy Chinese hamster ovary (CHO) cells. Based on earlier observations that some DNA probes show changes in fluorescence lifetime properties upon apoptosis $(40-42)$, we extended the study to cells that were induced to enter programmed cell death. Where necessary, observations were verified by dual-labeling experiments with probes of known labeling properties, i.e., DRAQ5 (a DNA probe; 43) and CMXRos (a mitochondrial probe; 15,44). Colocalization was present when energy transfer, as visualized by changes in the lifetime of SYTO13 fluorescence, occurred between both dyes or when structures coincided. We show that two-photon fluorescence lifetime imaging of
SYTO13 has potential for vital and differential imaging of DNA and RNA dynamics without damaging effects to the cells.

\section{MATERIALS AND METHODS Cell Cultures}

CHO cells were grown on coverslips in HAM's F12 medium (ICN Biomedicals, Costa Mesa, CA) supplemented with $10 \%$ fetal calf serum (FCS; Gibco Life Technologies, Paisley, UK) and $2 \mathrm{mM}$ L-glutamine. Cell cultures were maintained in an incubator at $5 \% \mathrm{CO}_{2}$ and $37^{\circ} \mathrm{C}$. Prior to apoptosis, cells were maintained overnight in HAM's F12 medium supplemented with $1 \%$ FCS and $2 \mathrm{mM}$ L-glutamine. Apoptosis was induced by the addition of staurosporin (1 $\mu \mathrm{M}$ final concentration, Sigma, Zwijndrecht, The Netherlands) $2 \mathrm{~h}$ before the imaging experiments started.

\section{Labeling Procedures and Sample Preparation}

To determine the lifetime characteristics of SYTO13 interacting with DNA or RNA, independent of its cellular environment, isolated DNA and tRNA were labeled with SYTO13 by the addition of the probe to DNA or tRNA in phosphate-buffered saline (PBS) to a final concentration of $2 \mu \mathrm{M}$. Yeast-tRNA $(10 \mathrm{mg} / \mathrm{ml})$ was obtained from Roche Molecular Biochemicals (Basel, Switzerland), whereas salmon testis DNA $(10 \mathrm{mg} / \mathrm{ml})$ was obtained from Sigma. SYTO13 (in dimethylsulfoxide [DMSO], 5mM) and CMXRos (in methanol, $5 \mathrm{mM}$ ) were obtained from Molecular Probes (Leiden, The Netherlands). DRAQ5 (5 mM in $\mathrm{HCl}$ ) was a gift from Prof. dr. Paul J. Smith (Department of Pathology, University of Wales, College of Medicine, Cardiff, UK).

Healthy and apoptotic cells were labeled by the addition of SYTO13-DMSO (final concentration $1 \mu \mathrm{M}$ ) to the cells on coverslips in medium. After 30 min of incubation, SYTO13 was washed away with probe-free medium and images were taken. Labeling of CHO cells with SYTO13 and repetitive imaging of the cells did not induce any morphological changes.

Using the standard labeling procedure (43) for the DNA probe, DRAQ5, cells die rapidly, presumably by necrosis. Therefore, an alternative staining procedure was developed. Healthy and apoptotic cells were stained with DRAQ5 by the addition of the probe to cells on coverslips in medium to a final concentration of $1 \mu \mathrm{M}$. After only 3 min, the staining medium was removed and replaced by fresh, probe-free medium. Applying this procedure, cells exhibited no morphological changes within the time span of the imaging experiments.

Dual labeling of cells with both SYTO13 and DRAQ5 was carried out by first labeling with SYTO13, followed by the addition of DRAQ5 according to the procedure described above. After only $3 \mathrm{~min}$, the staining medium containing both SYTO13 and DRAQ5 was removed and replaced by probe-free medium.

The mitochondria of apoptotic cells were labeled for $1 \mathrm{~h}$ by addition of CMXRos (15) to cells on coverslips in 
medium to a final concentration of $0.5 \mathrm{mM}$, prior to the addition of staurosporin. In dual-labeling experiments of CMXRos and SYTO13, the latter was added to cells already labeled with CMXRos prior to observation under the microscope, using the SYTO13 labeling procedure described above. Coverslips with either cells or droplets of isolated DNA/RNA solutions were mounted in a home-built sample holder and viewed under the microscope.

\section{Two-Photon Lifetime Microscopy}

Experiments were carried out on a home-built twophoton excitation inverted microscope as described in detail elsewhere (31). In short, the system is equipped with a mode-locked titanium:sapphire (Ti:Sa) laser (Tsunami, Spectra-Physics, Mountain View, CA) that produces 80 -fs pulses at a repetition rate of $82 \mathrm{MHz}$. After passing a beam expander and neutral density filters, the excitation light is directed to a dichroic mirror that is highly reflective in the near infrared and transparent below $700 \mathrm{~nm}$. Thus, the excitation light is reflected toward and focused by a $60 \times$ plan-apochromatic water-immersion objective (NA1.2, Nikon/Uvikon, Bunnik, The Netherlands) and scanned over the sample. The fluorescence light is collected by the same objective. The optical resolution was $0.27 \mu \mathrm{m}$ laterally and $0.72 \mu \mathrm{m}$ axially at an excitation wavelength of $800 \mathrm{~nm}$ (45). All fluorescence light below $700 \mathrm{~nm}$ is transmitted through the dichroic mirror described above and collected by a photomultiplier (Hamamatsu R1894, Toyooka Village, Japan) in photon counting mode. Additional blocking of excitation light is achieved by means of a series of 750-nm interference short pass filters in the imaging path behind the mirror. If desired, a more narrow emission wavelength range can be selected by placing additional interference (IF) or long pass (LP) filters (Optosigma, Santa Anna, CA) in the emission pathway.

All fluorescence (lifetime) imaging experiments were carried out at an excitation wavelength of $800 \mathrm{~nm}$. The fluorescence emission after pulsed excitation can be described by an exponential decay with a typical lifetime. Fluorescence lifetimes of commonly used dyes are typically on the order of a few nanoseconds. The method used here to determine the fluorescence lifetime is based on time-gated detection of the fluorescence. After each excitation pulse, the fluorescence decay is detected in four time-windows (gates) that are enabled sequentially, making the acquired lifetime intrinsically independent of laser intensity fluctuations. Details of the lifetime module are given elsewhere (14). The signal from many excitation pulses is integrated for each pixel. The integrated intensity in the four time gates is fitted to a monoexponential decay using a nonlinear least square Levenberg-Marquardt fit algorithm (46). The accumulated intensity of the four gates yields the fluorescence intensity for each pixel of the specimen. The fitted lifetime for every pixel results in the corresponding lifetime image. Error margins (SEM) are determined from the fit results within an area $(10 \times 10$ pixels) of similar lifetimes. Good quality fluorescence lifetime images of $256 \times 256$ pixels are recorded in about
30 s. All images shown are single-section images of a cell, thus utilizing the high axial resolution of two-photon excitation. In general, areas of short lifetime and high intensity are present next to areas of short lifetime and low intensity. A similar observation is made for long lifetimes. This indicates that the observed differences in lifetime are generally not correlated with intensity variations due to bleaching or differences in local probe concentrations. Data were processed using home-written programs under the IDL software package (Creaso B.V., Apeldoorn, The Netherlands).

\section{Fluorescence Spectra of SYTO13, DRAQ5, and CMXRos}

Two-photon excitation spectra may differ (in shape and peak wavelengths) from a doubled-wavelength version of the one-photon excitation spectra because the selection rules are different (36). Although the one-photon excitation spectra of the probes used here differ significantly from each other $(15,43)$, all appear to be excitable with two-photon excitation at $800 \mathrm{~nm}$. For CMXRos and DRAQ5, the obtained fluorescence intensity is relatively low.

Fluorophores show the same emission spectrum with either mode of excitation (36). Figure 1 shows the emission spectrum of SYTO13-DNA (15), CMXRos-methanol (15), and DRAQ5-PBS in solutions. Spectral measurements on DRAQ5 diluted in PBS $(1 \mu \mathrm{M})$ were carried out on an SPF-8100 series 2 fluorometer (SLM-Aminco, Beun de Ronde, Culemborg, The Netherlands). For determination of the emission spectrum, the probe was excited at 568 $\mathrm{nm}$. For the excitation spectrum, the emitted fluorescence was detected at $670 \mathrm{~nm}$. In cells, the emission spectra of SYTO13, CMXRos, and DRAQ5 were measured using a spectral microscope (7) with excitation at $488 \mathrm{~nm}$ for SYTO13 and CMXRos and $568 \mathrm{~nm}$ for DRAQ5 (spectra not shown). We found that the emission spectra of SYTO13 and CMXRos are unaltered in cells, whereas the emission spectrum of DRAQ5 shows a significant red shift of $20 \mathrm{~nm}$, in agreement with earlier observations (43). Apoptosis did not have an influence on the shape or peak positions of the emission spectra for any of the probes.

\section{Autofluorescence of CHO Cells}

We determined the intensity, wavelength range, and the lifetimes of the autofluorescence of healthy and apoptotic cells and compared them with the fluorescence characteristics of the various probes. Upon two-photon excitation with $800 \mathrm{~nm}$, both healthy and apoptotic $\mathrm{CHO}$ cells exhibit weak autofluorescence within the wavelength range of 500-600 nm. No autofluorescence was detected above $600 \mathrm{~nm}$. No differences in autofluorescence distribution and lifetimes between healthy and apoptotic cells were seen. Autofluorescence is distributed homogeneously over the cytoplasm, with occasionally scattered spots of higher intensity. The lifetime of the autofluorescence varies: $2.5 \pm 0.4 \mathrm{~ns}$ (diffuse) and $4.0 \pm$ $0.5 \mathrm{~ns}$ (spots). In an earlier study (34), the value of $2.2 \mathrm{~ns}$ 
FIG. 1. Emission spectra of the probes SYTO13-DNA $(\diamond$, excitation at $488 \mathrm{~nm}$ ), CMXRos-methanol ( $\square$, excitation at $488 \mathrm{~nm})$, and DRAQ5-PBS $(\bullet$, excitation at $568 \mathrm{~nm}$ ). Also indicated $(--)$ is the position of the $800-\mathrm{nm}$ excitation pulse in the two-photon experiments.

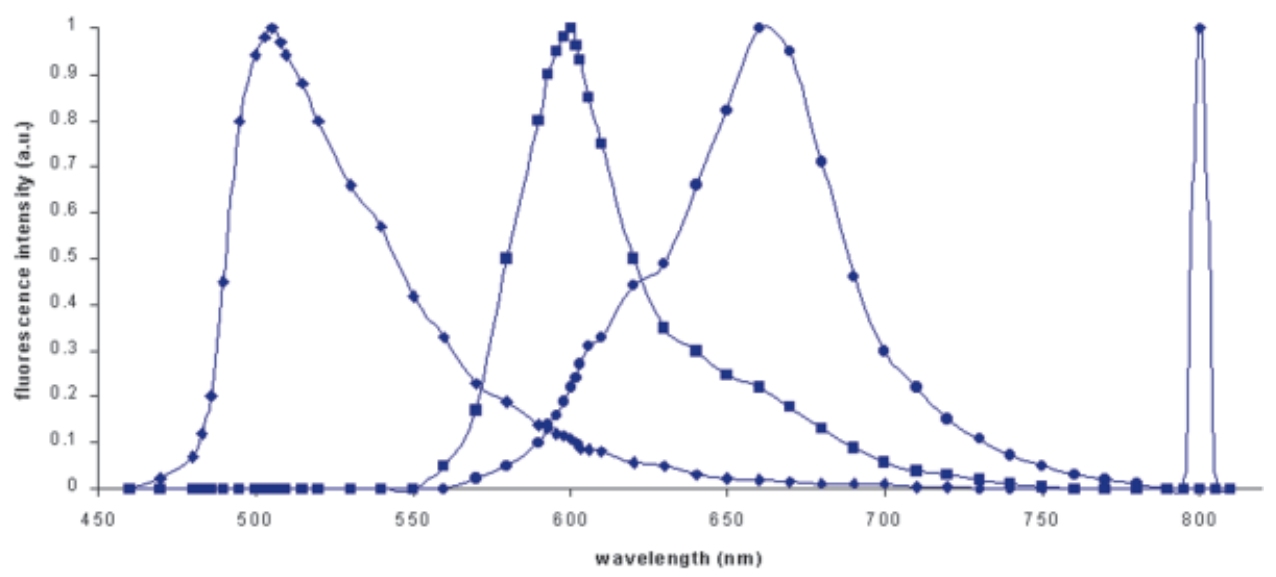

was attributed to the fluorescence of $\mathrm{NADH}$ binding to proteins (e.g., in the mitochondria).

\section{Use of Emission Filters in Single and Double-Probe Experiments}

On the basis of the overlap of the spectral region of cellular autofluorescence and the emission spectra of SYTO13 (for the latter, see Fig. 1), the use of an emission filter (IF530 \pm 60 ) $\mathrm{nm}$ for the suppression of autofluorescence relative to SYTO13 fluorescence is not possible. However, because the autofluorescence is very weak, a specific set-up configuration could be found (e.g., excitation light intensity, dwell time) in which autofluorescence did not exceed the detection limit and thus did not contribute to the fluorescence signal of SYTO13. In contrast, for the weakly fluorescent probes DRAQ5 and CMXRos, the filters LP650 and IF600 $\pm 30 \mathrm{~nm}$ had to be used, respectively, to suppress the contribution of autofluorescence.

In the colocalization experiments, cells were labeled simultaneously with two probes (SYTO13/DRAQ5 and SYTO13/CMXRos). In these pairs, the probes have different emission characteristics (Fig. 1) and, therefore, the emission filters given above can be used to separate their fluorescence. Sequential observation through either of the filters now allows colocalization of the probes.

\section{RESULTS}

\section{Observations on Isolated DNA and tRNA Labeled with SYTO13}

The fluorescence lifetime of SYTO13 bound to isolated DNA in PBS was $2.8 \pm 0.1 \mathrm{~ns}$, whereas a lifetime of $4.2 \pm$ 0.1 ns was found for SYTO13 bound to isolated tRNA in PBS. Unlabeled DNA and tRNA did not exhibit autofluorescence, as concluded from the absence of a detectable fluorescence signal under the microscope.

\section{Distribution of SYTO13 in Healthy Cells}

Figure 2 shows the distribution of SYTO13 in healthy $\mathrm{CHO}$ cells as the fluorescence intensity (Fig. 2A) and lifetime (Fig. 2B) images of a single xy-plane. In the inten- sity image, the strong fluorescence of the nucleus and subnuclear structures, such as the nucleoli, are clearly discernible from the weaker cytoplasmic fluorescence. It should be noted that cytoplasmic SYTO13 fluorescence is much stronger than cellular autofluorescence. In the lifetime image, three lifetime values are found, i.e., $3.4 \pm 0.2$ ns for the nucleus and small spots in the cytoplasm, $4.1 \pm$ $0.1 \mathrm{~ns}$ for the cytoplasm, and $3.8 \pm 0.1 \mathrm{~ns}$ for the nucleoli (Table 1).

On the basis of the known labeling behavior of SYTO13 (15), its lifetime distribution as described above, and the differences found in lifetime for SYTO13 attached to isolated DNA and tRNA, we attribute the $3.4 \pm 0.2$ ns lifetime to its interaction with DNA and the $4.1 \pm 0.2$ ns lifetime to its interaction with RNA. The DNA spots in the cytoplasm, which are not seen in the intensity images, most probably represent mitochondrial DNA. Because nucleoli contain both RNA and DNA, their lifetime value was found to be in between that of DNA and RNA, $3.8 \pm 0.2 \mathrm{~ns}$.

\section{Verification Based on DRAQ5 (Co)labeled Healthy Cells}

To confirm the suggested distribution of SYTO13 in healthy cells, we performed labeling experiments on cells with the highly specific DNA probe, DRAQ5. The nucleus is labeled uniformly, with a homogeneous fluorescence lifetime of $0.4 \pm 0.1 \mathrm{~ns}$ (Table 1, images not shown). From these results it is obvious that DRAQ5 does not significantly stain RNA, nor can it interact with mitochondrial DNA. Although an earlier study (43) suggested weak RNA labeling, the absence of significant RNA staining here is probably due to the short labeling procedure used.

Simultaneous labeling of healthy $\mathrm{CHO}$ cells with SYTO13 and DRAQ5 (Fig. 3) resulted in a significant decrease of the SYTO13 fluorescence intensity in the nucleus and nucleoli as compared with that in the cytoplasm (Fig. 3A, through an IF530 filter). The nucleus shows a significantly shortened SYTO13 lifetime of $1.7 \pm 0.1 \mathrm{~ns}$, whereas the nucleoli have a lifetime of $3.0 \pm 0.2 \mathrm{~ns}$ (Fig. $3 \mathrm{~B}$, observation at $530 \mathrm{~nm}$, Table 1). The sites of intensity decrease and lifetime shortening corresponds to the sites 


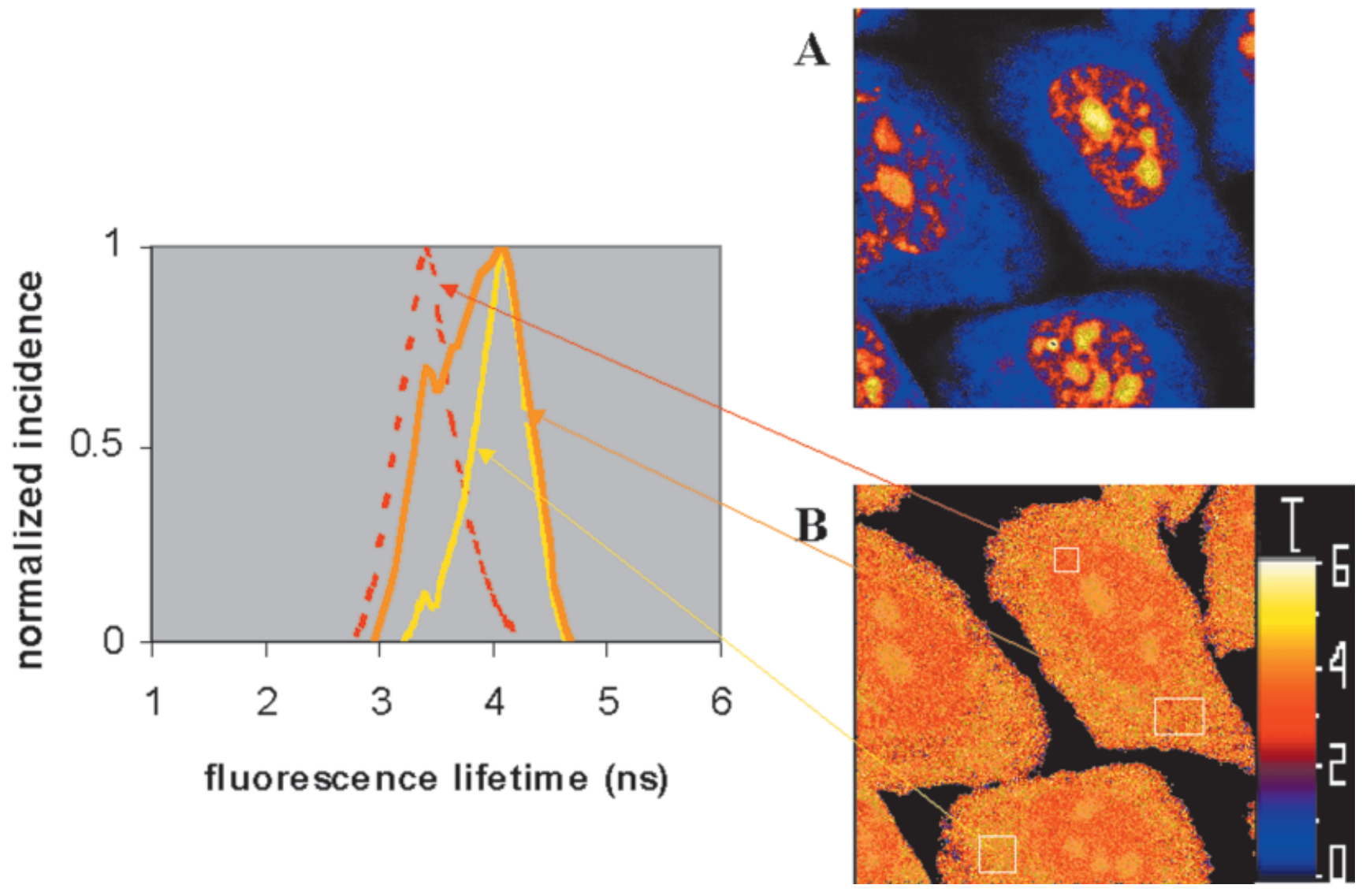

FIG. 2. Distribution of SYTO13 in healthy CHO cells (single-section xy image, $40 \times 40 \mu \mathrm{m}$ ). No emission filters are used. A: Intensity image. B: Lifetime image. The inset shows the distribution of lifetimes as found in various parts of the cell: nucleus (top square), cytoplasm (bottom square), and cytoplasm plus mitochondria (middle square). See Table 1 for lifetimes. (Color figure can be viewed in the online issue, which is available at www.interscience. wiley.com.)

of DRAQ5 labeling (Fig. 3C,D, through an LP650 filter). In the nucleus, only a uniform DRAQ5 fluorescence with a lifetime of $0.4 \pm 0.1 \mathrm{~ns}$ is observed (Table 1). These observations can only be fully understood in the light of Förster resonance energy transfer (FRET; 47-52) from SYTO13 to DRAQ5. In the nucleus, SYTO13 colocalizes

Table 1

Lifetimes of SYTO13 and DRAQ5 in Healthy and Apoptotic Cells*

\begin{tabular}{|c|c|c|c|c|c|c|c|c|}
\hline \multicolumn{4}{|c|}{ Healthy cells } & & \multicolumn{4}{|c|}{ Apoptotic cells } \\
\hline SYTO13 & DRAQ5 & $\begin{array}{c}\text { SYTO13 } \\
\text { double-labeled } \\
\text { cell } \\
\end{array}$ & $\begin{array}{c}\text { DRAQ5 } \\
\text { double-labeled } \\
\text { cell }\end{array}$ & & SYTO13 & DRAQ5 & $\begin{array}{c}\text { SYTO13 } \\
\text { double-labeled } \\
\text { cell } \\
\end{array}$ & $\begin{array}{c}\text { DRAQ5 } \\
\text { double-labeled } \\
\text { cell } \\
\end{array}$ \\
\hline $3.4(0.2)$ & $0.4(0.1)$ & $1.7(0.1)^{\mathrm{a}}$ & $0.4(0.1)$ & Nucleus & $\begin{array}{c}\text { Early stage } \\
3.4(0.2) \\
\text { Later stage } \\
2.6(0.1)^{\mathrm{b}}\end{array}$ & $0.4(0.1)$ & $1.8(0.2)^{\mathrm{a}}$ & $0.4(0.1)$ \\
\hline $3.8(0.1)$ & - & $3.0(0.2)^{\mathrm{a}}$ & - & Nucleoli & $3.8(0.1)$ & - & $2.8(0.1)^{\mathrm{a}}$ & - \\
\hline $4.1(0.2)$ & - & $4.0(0.2)$ & - & Cytoplasm & $4.1(0.2)$ & - & $4.0(0.2)$ & - \\
\hline $3.4(0.2)$ & - & $3.4(0.2)$ & - & $\begin{array}{l}\text { Spots in } \\
\text { cytoplasm }\end{array}$ & $3.4(0.1)$ & - & $3.4(0.2)$ & \\
\hline- & - & - & - & $\begin{array}{l}\text { Cluster in } \\
\text { cytoplasm }\end{array}$ & $\begin{array}{c}\text { Early stage } \\
3.4(0.2) \\
\text { Later stage } \\
2.0(0.1)^{\mathrm{b}}\end{array}$ & - & $2.0-3.4$ & - \\
\hline
\end{tabular}

${ }^{*}$ SEM are indicated in parentheses. ${ }^{\mathrm{a} C h a n g e s}$ are significant as related to the values observed in single-labeled cells. ${ }^{\mathrm{b}} \mathrm{Changes}$ are significant as related to the advancement of apoptosis. 

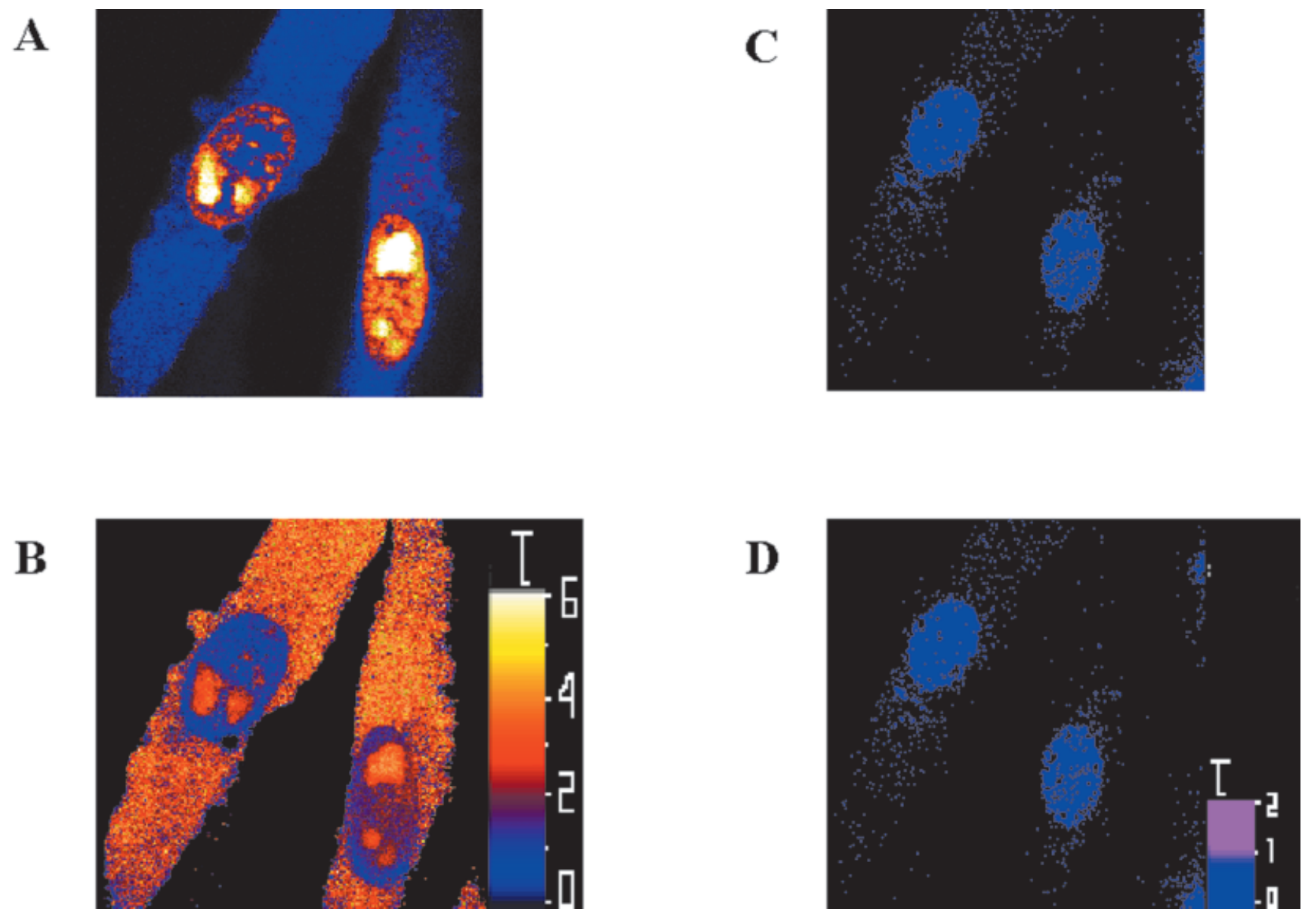

FIG. 3. Distribution of SYTO13 and DRAQ5 in healthy CHO cells (single-section xy image, $40 \times 40 \mu \mathrm{m}$ ). A: Intensity image of SYTO13 distribution as observed through an IF530 filter. B: Lifetime image of SYTO13 distribution as observed through an IF530 filter. C: Intensity image of DRAQ5 distribution as observed through an LP650 filter. D: Lifetime image of DRAQ5 distribution as observed through an LP650 filter. See Table 1 for lifetimes. (Color figure can be viewed in the online issue, which is available at www.interscience.wiley.com.)

with DRAQ5 and FRET from SYTO13 to DRAQ5 takes place. As a result, the fluorescence intensity of SYTO13, as observed through the IF530 filter, decreases. Furthermore, SYTO13 fluorescence lifetime shortens both in the nucleus and nucleoli because an extra deactivation channel is present. One of the prerequisites for FRET to take place is an overlap of the emission spectrum of the donor (SYTO13) and the single-photon excitation spectrum of the acceptor (DRAQ5). Indeed, such an overlap is present (Fig. 4). Because close proximity of donor and acceptor probe is another basic prerequisite for FRET, its detection is proof of colocalization of SYTO13 and DRAQ5 (and thus DNA) in the nucleus, including nucleoli.

In the cytoplasm, including mitochondria, no DRAQ5 is found and the intensities and lifetimes of SYTO13 are unchanged (Table 1).

\section{Distribution of SYTO13 in Apoptotic Cells}

To determine the changes in distribution and lifetimes of SYTO13 fluorescence during the early phases of apoptosis, we labeled $\mathrm{CHO}$ cells several hours after the addition of staurosporin (53). We observed changes in the cellular morphology in the intensity images (Fig. 5A,C) that are typical of the early stages of apoptosis $(53,54)$. These include the condensation of nuclear DNA and blebbing of the plasma membrane. These changes are not caused by SYTO13 because they are not observed in healthy SYTO13-labeled control cells. The lifetime images of apoptotic SYTO13-labeled cells (Fig. 5B,D) confirm the morphological features, but are also indicative of the presence of large cytoplasmic clusters of SYTO13 with a fluorescence lifetime equal to that of SYTO13 associated with DNA, i.e., $3.4 \pm 0.2$ ns. These clusters are not observed in the intensity image. The lifetime value of SYTO13 in the nucleus seems to shorten slightly upon advancement of apoptosis, whereas that associated with the clusters in the cytoplasm shortens to $2.0 \pm 0.2 \mathrm{~ns}$ (Table 1).

\section{Verification Based on DRAQ5 (Co)labeled Apoptotic Cells}

In single DRAQ5-labeling experiments on the apoptotic cells, a homogeneous labeling of the nucleus with DRAQ5 (not shown), with a lifetime of $0.4 \pm 0.1 \mathrm{~ns}$, is observed 


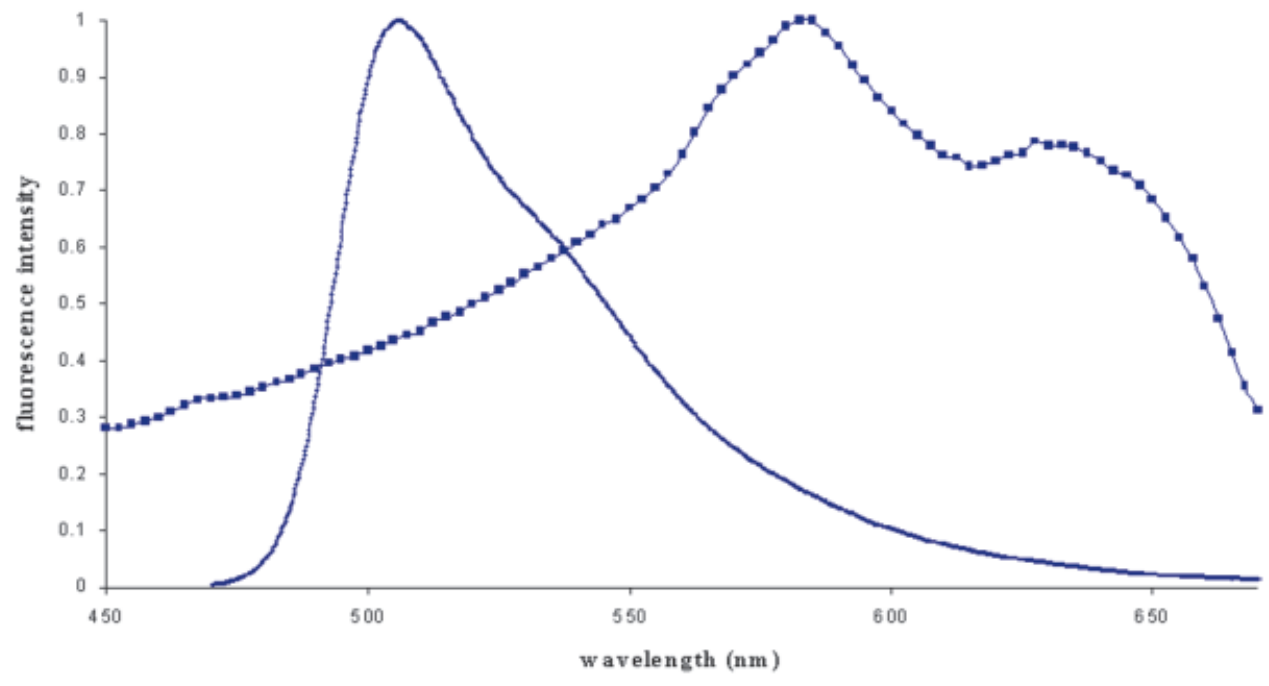

FIG. 4. Emission spectrum of SYTO13 ( $\bullet$ excitation at $488 \mathrm{~nm}$ ) and single-photon excitation spectrum of DRAQ5-PBS (ם, emission at $650 \mathrm{~nm})$.

(Table 1). The absence of significant fluorescence intensity in the cytoplasm strongly suggests that no DNA of nuclear origin has dispersed into the apoptotic cytoplasm.
This was confirmed in the SYTO13/DRAQ5 colocalization experiments, the results of which are shown in Figure 6. The relative nuclear fluorescence intensity of

\section{A}
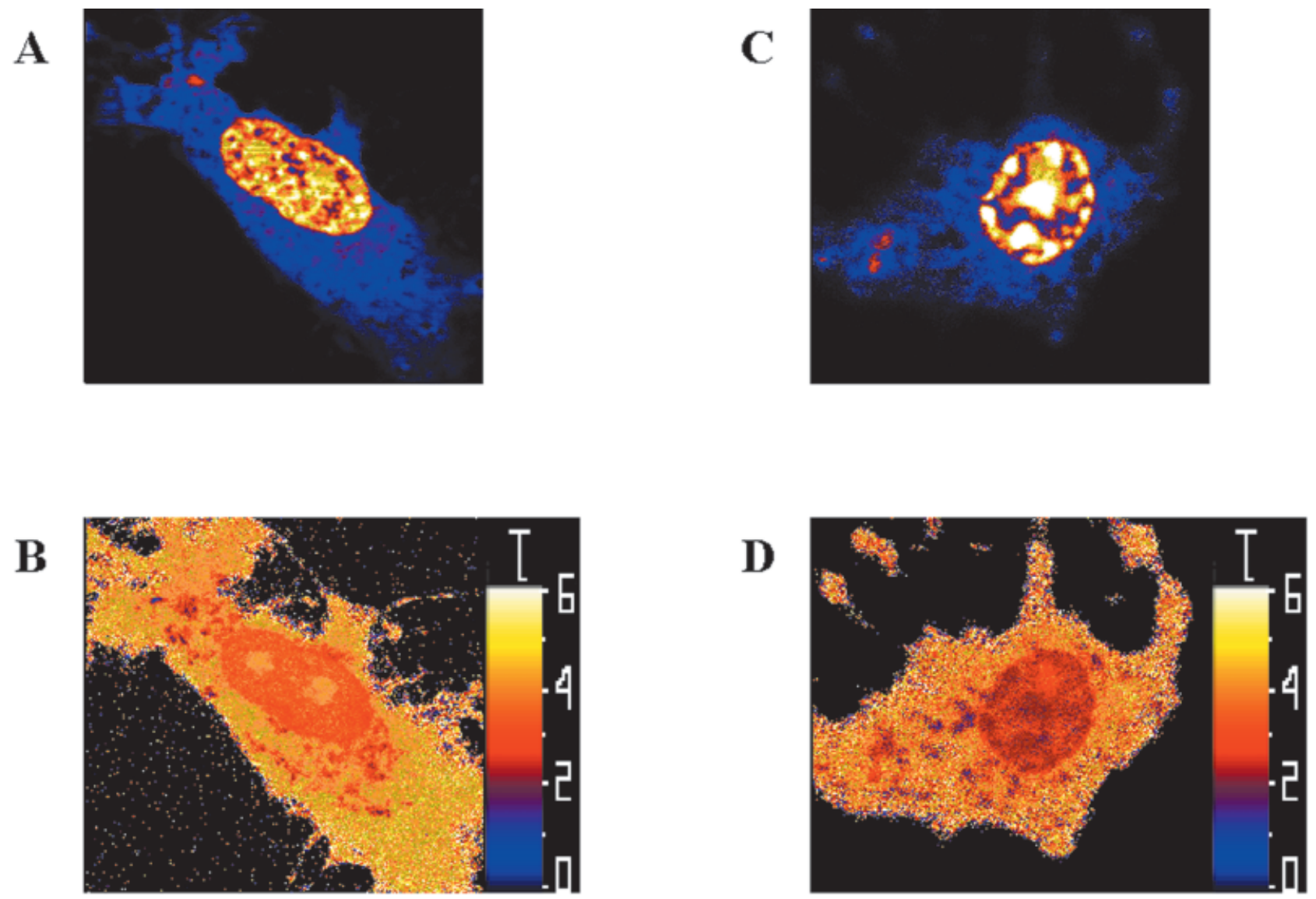

FIG. 5. Distribution of SYTO13 in apoptotic CHO cells (single-section xy image, $40 \times 40 \mu \mathrm{m}$ ). No emission filters were used. Two cells in different apoptotic stages are shown: left images approximately $2 \mathrm{~h}$ after the addition of staurosporin, early stage of apoptosis; right images more than $3 \mathrm{~h}$ after the addition of staurosporin, later stage of apoptosis. A,C: Intensity image. B,D: Lifetime image. Representative lifetimes of the nucleus and clusters in the cytoplasm in image B are $3.4(0.2)$ ns. In image D, the representative lifetimes are $2.6(0.2)$ ns (nucleus) and $2.0(0.2)$ ns (clusters). see Table 1. 

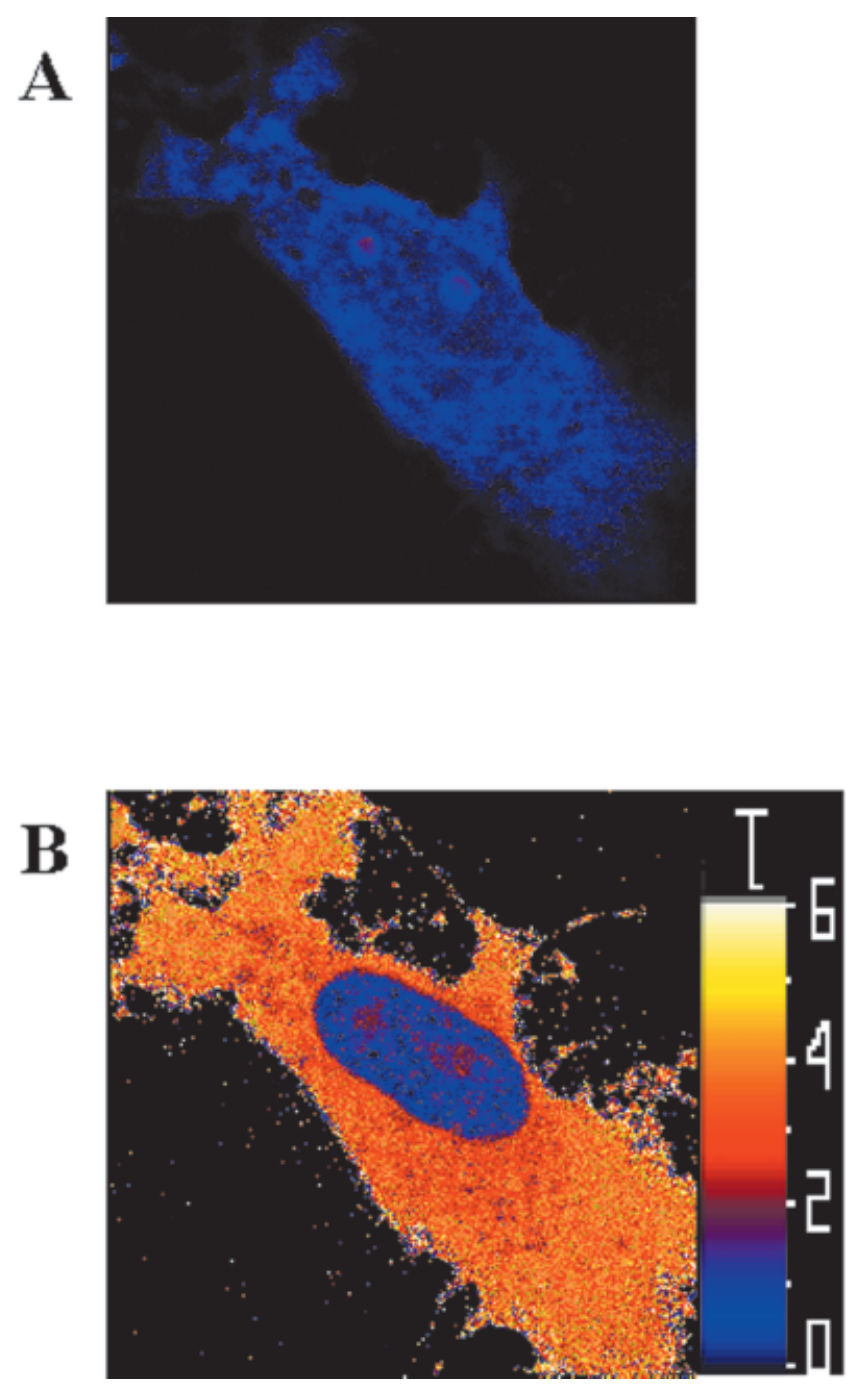

FIG. 6. Distribution of SYTO13 in apoptotic dual labeled CHO cells (single-section $\mathrm{xy}$ image, $40 \times 40 \mu \mathrm{m}$ ). A: Intensity image of SYTO13 distribution as observed through an IF530 filter. B: Lifetime image of SYTO13 distribution as observed through an IF530 filter. See Table 1. (Color figure can be viewed in the online issue, which is available at www.interscience.wiley.com.)

SYTO13 (IF530 filter, Fig. 6A) compared with that in the cytoplasm is decreased. In the nucleus, SYTO13 lifetimes (Fig. 6B, Table 1) are shortened to $1.8 \pm 0.2 \mathrm{~ns}$ (overall nucleus) and $2.8 \pm 0.1 \mathrm{~ns}$ (nucleoli). The DRAQ5 fluorescence passing the LP650 filter (images not shown, Table 1 ) is only seen in the nucleus, having a lifetime of $0.4 \pm$ 0.1 ns. Again, in the nucleus and nucleoli, SYTO13 and DRAQ5 are colocalized, resulting in FRET from SYTO13 to DRAQ5.

The lifetime of SYTO13 in the cytoplasm of duallabeled cells remains $4.0 \mathrm{~ns}$, with large clusters of SYTO13 fluorescence having lifetimes of 2.0-3.4 ns. Again, in the cytoplasm, no DRAQ5 staining is detected. We conclude that the large clusters with a short SYTO13 lifetime in the cytoplasm do not represent DNA of nuclear origin.

\section{Verification of Mitochondrial Clustering in Apoptotic Cells With CMXRos and SYTO13}

Because these large cytoplasmic clusters of SYTO13 with a short lifetime in apoptotic cells might originate from the clustering of mitochondria, we labeled apoptotic cells with the mitochondrial stain, CMXRos (Fig. 7). Mitochondrial clusters are recognized in the apoptotic cell (Fig. 7A). The lifetime of these clusters varies between 4.5 and 5.5 ns (not shown). The most intense clusters are indicated by numbers 1 to 7 . Figure $7 \mathrm{~B}$ shows the fluorescence intensity of SYTO13 of that same cell after the addition of SYTO13. The nucleus is intensely fluorescent (lifetime $3.2 \pm 0.2 \mathrm{~ns}$ ), whereas the cytoplasm shows a weak, but significant, fluorescence intensity (lifetime $4.2 \pm 0.2 \mathrm{~ns})$. In the cytoplasm, clusters with a shorter lifetime (less than $3.2 \mathrm{~ns}$ ) are present. Figure $7 \mathrm{C}$ highlights the positions in the CMXRos/SYTO13-labeled cell with a fluorescence lifetime of SYTO13 below 3.2 ns. The seven clusters indicated in Figure $7 \mathrm{~A}$ are clearly present. Note that there are some extra clusters visible in Figure $7 \mathrm{C}$ compared with Figure 7A. Probably the cell has moved a little, so that some new mitochondrial clusters come into focus.

We note that after the addition of SYTO13, no FRET from SYTO13 to CMXRos is observed. We conclude that in apoptotic cells, the cytoplasmic clusters with short lifetimes of SYTO13 do colocalize with the mitochondria, but that the proximity or relative orientation of CMXRos and SYTO13 in the mitochondria is such that no FRET can occur.

\section{DISCUSSION}

SYTO13 appears to be a highly specific lifetime probe that allows simultaneous and differential imaging of DNA and RNA in living cells. Associated with cellular DNA (nucleus, mitochondria), SYTO13 has a fluorescence lifetime that differs significantly from that when associated with cellular RNA (cytoplasm). A similar difference in lifetimes of SYTO13 is found when attached to isolated DNA $(2.8 \pm 0.1 \mathrm{~ns})$ and isolated tRNA $(4.2 \pm 0.1 \mathrm{~ns})$. In the nucleoli, both DNA and RNA are present and an average lifetime close to that when attached to RNA is found. Because adequate information about the relative binding affinities of SYTO13 to DNA and RNA is lacking, the relative DNA/RNA composition of the nucleoli cannot yet be determined from the lifetime in the nucleoli. However, the lifetime being so close to that of SYTO13/RNA indicates that in the nucleoli high amounts of RNA are found.

Several hours after initiation of apoptosis, the typical morphological changes of early apoptosis appear. Moreover, clusters of SYTO13 with shorter lifetime are found in the cytoplasm. Most probably, these clusters represent staining of mitochondrial DNA, as concluded from duallabeling experiments with DRAQ5 and CMXRos. When the apoptotic process advances, the lifetime of the clusters shortens significantly, as does the lifetime of SYTO13 attached to DNA in the nucleus. Explanation of this phe- 


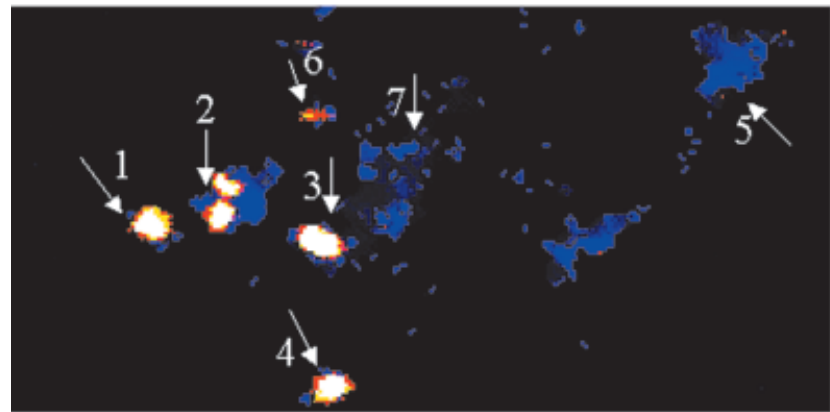

A
B
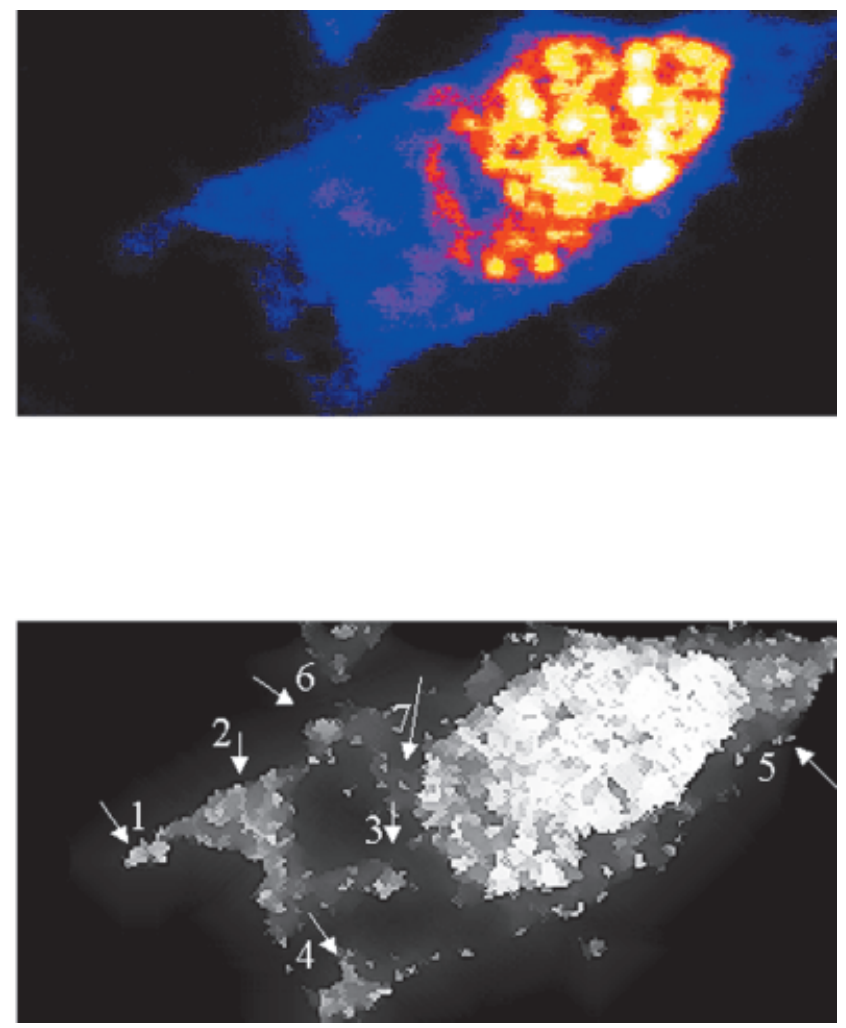

FIG. 7. A: Distribution of CMXRos in apoptotic CHO cells (single-section xy image, $20 \times 30 \mu \mathrm{m}$ ) observed through an IF600 filter. Arrows and numbers indicate clustered mitochondria. B,C: Images of the same cell, now SYTO13/CMXRos labeled and observed through an IF530 filter. Image B is the intensity image. Image $\mathrm{C}$ highlights the spots where the lifetime is smaller than $3.2 \mathrm{~ns}$. These include the nucleus and, indicated by numbers as in image $\mathrm{A}$, the clustered mitochondria. Note that the cell has slightly turned in between image A and images B,C. (Color figure can be viewed in the online issue, which is available at www.interscience.wiley.com.)

nomenon requires a full characterization study of SYTO13 attached to DNA and RNA under various circumstances. We speculate that one of the possible causes is selfquenching due to changes in the interprobe distance due to the condensation of DNA. Similar changes in fluorescence lifetimes of DNA probes in apoptotic cells were reported $(40-42)$ in flow cytometric experiments. Thus, the phenomena observed here can also be detected in cytometric experiments and thus might allow for in vivo lifetime-based detection of apoptosis of cell sorting by flow cytometry.

We colocalized DRAQ5 and SYTO13 bound to nuclear DNA in the dual-labeling experiments of $\mathrm{CHO}$ cells by the observation of FRET from SYTO13 to DRAQ5 within the nucleus. The question arises: How do we distinguish the occurrence of FRET between SYTO13 and DRAQ5 from the release of SYTO13 upon entrance of DRAQ5 into the cells? In the latter situation, a decrease in SYTO13 fluorescence would have been observed, due to decreased availability of SYTO13. However, in that situation, no change in SYTO13 fluorescence lifetime (observed through an IF530 filter) would have been detected. Note that the combination of spectral and lifetime contrast is crucial in our experiments: only by applying an IF filter were we able to separate SYTO13 fluorescence from the fluorescence of DRAQ5.
Various probes (15) may be used to simultaneously image DNA and RNA in cells. Many of these probes are toxic to cells (DRAQ5 [43], the TOTO-family), require ultraviolet (UV) excitation (the Hoechst family, DAPI), or can only be applied to dead cells (7-AAD, propidium iodide, ethidium bromide). For vital imaging of DNA and RNA over prolonged periods of time, only a few probes are suited, i.e., acridine orange, LDS751, and probes of the SYTO family. However, acridine orange and LDS751 lack specificity because they also label other cellular constituents such as granules or the endoplasmic reticulum (22). We have shown that the application of lifetime contrast to SYTO13 allows dynamic and simultaneous assessment of processes involving changes in either DNA or RNA. Similarly, other cellular characteristics may be investigated, provided that suitable lifetime probes are found. This indicates the high potential of lifetime imaging techniques for the study of dynamic processes in vital cells.

In this study, lifetime imaging was combined with twophoton excitation, thus utilizing the femtosecond pulsed laser required for the latter process. Two-photon excitation microscopy is used widely in life sciences because it allows the combination of high axial resolution and repetitive imaging of cells without seriously affecting their vitality. We did not attempt to compare the amount of cell damage induced by single and two-photon excitation. 
However, no morphological changes in cells were detected in our studies, even after prolonged and repetitive imaging.

\section{ACKNOWLEDGMENTS}

We greatly acknowledge Dr. B. Schutte for his technical advice and fruitful discussions.

\section{LITERATURE CITED}

1. Misteli T, Spector D. The cellular organization of gene expression. Curr Opin Cell Biol 1998;10:323-331.

2. Halicka D, Bedner E, Darwzynkiewicz Z. Segregation of RNA and separate packaging of DNA and RNA in apoptotic bodies during apoptosis. Exp Cell Res 2000;260:248-256.

3. Leonhardt H, Rahn H, Cardoso M. Functional links between nuclear structure, gene expression, DNA replication and methylation. Crit Rev Eukaryot Gene Expr 1999;9:345-351.

4. Ma H, Samarabandu J, Devdhar R, Acharya R, Cheng P, Meng C, Berezney R. Spatial and temporal dynamics of DNA replication sites in mammalian cells. Cell Biol 1998;43:1415-1425.

5. Kennedy B, Barbie D, Classon M, Dyson N, Harlow E. Nuclear organization of DNA replication in primary mammalian cells. Genes Dev 2000;14:2855-2868.

6. Tsien R, Poenie M. Fluorescence ratio imaging: a new window into intracellular ionic signalling. Trends Biochem Sci 1986;11:450-455.

7. Frederix P, Asselbergs M, van Sark W, van den Heuvel D, Hamelink W, de Beer E, Gerritsen H. A high sensitivity spectrograph for use in fluorescence microscopy. Appl Spectrosc (in press).

8. Verveer P, Squire A, Bastiaens P. Global analysis of fluorescence lifetime imaging microscopy data. Biophys J 2000;78:2127-2137.

9. Squire A, Verveer P, Bastiaans P. Multiple frequency fluorescence lifetime imaging microscopy. J Microsc 2000;197-2:136-149.

10. French T, So P, Dong C, Berland K, Gratton E. Fluorescence lifetime imaging techniques for microscopy. Methods Cell Biol 1998;56:277304.

11. Lakowicz J, Szmacinski H, Nowaczyk K, Berndt K, Johnson M. Fluorescence lifetime imaging. Anal Biochem 1992;202:316-330.

12. So P, French T, Yu W, Berland K, Dong C, Gratton E. Time-resolved fluorescence microscopy using two-photon excitation. Bioimaging 1995;3:49-63.

13. Buurman E, Sanders R, Draaijer A, Gerritsen H, van Veen J, Houpt P, Levine Y. Fluorescence lifetime imaging using a confocal laser scanning microscope. Scanning 1992;9:152-159.

14. de Grauw C, Gerritsen H. A multiple time-gated module for fluorescence lifetime imaging. Appl Spectrosc (in press).

15. Haugland R. Nucleic acid detection. In: Spence MTZ, editor. Handbook of fluorescent probes and research chemicals, $6^{\text {th }}$ edition. Eugene, OR: Molecular Probes; 1996. p 143-178. See also www.molecularprobes.com

16. US Patents Nos. 5,436, 34; 5,445,946 and patents pending

17. French T, So P, Weaver D, Coelho-sampaio T, Gratton E, Voss E, Carrero J. Two-photon fluorescence lifetime imaging microscopy of macrophage-mediated antigen expression. J Microsc 1996;185:339353.

18. Lin H, Scmacinski H, Lakowicz J. Lifetime-based pH sensors: indicators for acidic environments. Anal Biochem 1999;269:162-167.

19. Sanders R, Gerritsen H, Draaijer A, Houpt P, Levine Y. Quantitative $\mathrm{pH}$ imaging in cells using confocal fluorescence lifetime imaging microscopy. Anal Biochem 1995;227:302-308.

20. Herman B, Wodnicki P, Seongwook K, Periasamy A, Gordon G, Mahajan N, Wang X. Recent developments in monitoring calcium and protein interactions in cells using fluorescence lifetime microscopy. J Fluoresc 1997;7:85-91.

21. Sanders R, Gerritsen H, Draaijer A, Houpt P, Levine Y. Fluorescence lifetime imaging of free calcium in single cells. Bioimaging 1994;2: $131-138$.

22. Szmacinski H, Lakowicz J. Fluorescence lifetime-based sensing and imaging. Sensors Actuators B 1995;29:16-24.

23. Oida T, Sako Y, Kusimi A. Fluorescence lifetime imaging microscopy (flimscopy). Biophys J 1993;64:676-685.

24. Lakowicz J, Szmacinski H, Nowaczyk K, Johnson M. Fluorescence lifetime imaging of calcium using Quin-2. Cell Calcium 1992;13:131147.

25. Lakowicz J, Szmacinski H, Nowaczyk K, Lederer W, Kirby M, Johnson
M. Fluorescence lifetime imaging of intracellular calcium in COS cells uning Quin-2. Cell Calcium 1994;15:7-27.

26. Szmacinski H, Lakowicz J. Sodium green as a potential probe for intracellular sodium imaging based on fluorescence lifetime. Anal Biochem 1997;250:131-138.

27. Despa S, Vecer J, Steels P, Ameloot M. Fluorescence lifetime microscopy of the $\mathrm{Na}+$ indicator sodium green in HeLa cells. Anal Biochem 2000;281:159-175.

28. Lakowicz J. Principles of fluorescence spectroscopy. New York: Plenum Press; 1999. 698 p.

29. Morgan C, Mitchell A, Murray J. Nano second time-resolved fluorescence microscopy: principles and practice. Trans $\mathrm{R}$ Microsc Soc 1996;90:463-466.

30. Wouters F, Bastiaans P. Fluorescence lifetime imaging of receptor tyrosine kinase activity in cells. Curr Biol 1999;9:1127-1130.

31. Sytsma J, Vroom J, de Grauw C, Gerritsen H. Time-gated fluorescence lifetime imaging and microvolume spectroscopy using two-photon excitation. J Microsc 1998;191:39-51.

32. Denk W, Stickler J, Webb W. Two-photon laser scanning fluorescence microscopy. Science 1990;248:73-76.

33. Jakobs S, Subramaniam V, Schönle A, Jovin T, Hell S. EGFP and DsRed expressing cultures of Escherichia coli imaged by confocal, twophoton and fluorescence lifetime microscopy. FEBS Lett 2000;479: 131-135.

34. Konig K. Multiphoton microscopy in life sciences. J Microsc 2000; 200:83-104.

35. Straub M, Lodemann P, Holroyd P, Jahn R, Hell S. Live cell imaging by multifocal multiphoton microscopy. Eur J Cell Biol 2000;79:726-734.

36. Fan G, Fujisaki H, Miyawaki A, Tsay R, Tsien R, Ellisman M. Video-rate scanning two-photon excitation microscopy and ratio imaging with cameleons. Biophys J 1999;76:2412-2420.

37. Williams R, Piston D, Webb W. Two-photon molecular excitation provides intrinsic 3-dimensional resolution for laser-based microscopy and microphotochemistry. FASEB J 1994;8:804-813.

38. Patterson G, Piston D. Photobleaching in two-photon excitation microscopy. Biophys J 2000;78:2159-2162.

39. Squirrell J, Wokosin D, White J, Bavister B. Long-term two-photon fluorescence imaging of mammalian embryos without compromising viability. Nature Biotechnol 1999;17:763-767.

40. Frey T. Nucleic acid dyes for detection of apoptosis in live cells. Cytometry 1995;21:265-274.

41. Sailer B, Steinkamp J, Crissman H. Flow cytometric fluorescence lifetime analysis of DNA-binding probes. Eur J Histochem 1998;42: $19-27$.

42. Kirschstein O, Sip M, Kittler L. Quantitative and sequence-specific analysis of DNA-ligand interaction by means of fluorescent intercalator probes. J Mol Recognit 2000;13:157-163.

43. Smith P, Wiltshire M, Davies S, Patterson L, Hoy T. A novel cell permeant and far-red fluorescent DNA probe, DRAQ5, for blood cell discrimination by flow cytometry. J Immunol Methods 1999;229:131139.

44. US Patents Nos. 5,459,268 and other patents pending

45. de Grauw C, Vroom J, van der Voort H, Gerritsen H. Imaging properties in two-photon excitation microscopy and effects of refractive index mismatch in thick specimen. Appl Optics 1999;38:5995-6003.

46. Press W, Teulolsky S, Vettering W, Flannery B. Numerical recipes in $\mathrm{C}$ : the art of scientific computing. Cambridge: University Press; $1992.152 \mathrm{p}$.

47. Förster Th. Intermolecular energy transfer and fluorescence. Ann Phys 1948;2:55-73.

48. Förster Th. Transfer mechanisms of electronic excitation energy. Radiat Res 1960 (Suppl.);2:326-339.

49. Förster Th. Mechanisms of energy transfer. Comp Biochem 1967;22: 61-78.

50. van Zandvoort M, Wróbel D, Lettinga $P$, van Ginkel G, Levine Y. Chlorophylls in polymers. I. State of chlorophyll a in unstretched polymer systems. Photochem Photobiol 1995;62:279-289.

51. Murata S, Herman P, Lin H, Lakowicz J. Fluorescence lifetime imaging of nuclear DNA: effect of fluorescence resonance energy transfer. Cytometry 2000;41:178-185.

52. Knoester J. Incoherent energy transfer in disordered systems. Utrecht: Thesis University of Utrecht; 1987. $152 \mathrm{p}$

53. Yoshida M, Usui T, Tsujimura K, Inagaki M, Beppu T, Horinouchi S. Biochemical differences between staurosporine-induced apoptosis and premature mitosis. Exp Cell Res 1997;232:225-239.

54. Kockx M, Knaapen M. The role of apoptosis in vascular disease. J Pathol 2000;190:267-281. 